\title{
W/EUROFER functionally graded coatings for plasma facing components: technology transfer to industry and upscaling
}

\author{
Thilo Grammes $^{1 *}$, Thomas Emmerich ${ }^{1}$, Jarir Aktaa ${ }^{1}$ \\ ${ }^{1}$ Institute for Applied Materials - Materials and Biomechanics, Karlsruhe Institute of Technology, Hermann-von-Helmholtz-Platz 1, \\ 76344 Eggenstein-Leopoldshafen, Germany \\ *Corresponding Author: Thilo Grammes (thilo.grammes@kit.edu)
}

\section{Abstract}

The tritium breeding blanket is a vital component of future fusion reactors, providing the fuel for the fusion reaction. Tungsten is a viable coating material to protect its first wall from erosion by plasma. The feasibility of applying tungsten coatings by vacuum plasma spraying has already been demonstrated, using a functionally graded material of mixed tungsten and EUROFER97 steel as connecting layer to mitigate a thermal expansion mismatch. This technology was now transferred to industrial level to enable further upscaling. Samples of three different sizes were coated, the largest ones measuring $500 \times 250 \mathrm{~mm}^{2}$ and containing mock-up cooling channels. The sample distortion was found to be small. An ultrasonic analysis did not reveal any delamination but indicated potential weaker spots in the corners that may have been subjected to faster cooling. Both the coating's thickness of $2 \mathrm{~mm}$ and linear chemical gradation over five interlayers met well with specifications, as verified by scanning electron microscopy, energy-dispersive $\mathrm{X}$ ray spectroscopy as well as image thresholding analysis. The microstructure consisted of typical splatshaped particles of tungsten and EUROFER, with minor porosity only. In total, these first results indicate that good coating quality can be achieved even in dimensions approaching fusion-relevant size.

Keywords: functionally graded material (FGM), plasma spraying, first wall, tungsten, EUROFER, plasma-facing components.

\section{Introduction}

In future fusion reactors such as DEMO, the first wall panels of tritium breeding units will be subject to substrantial sputtering erosion [1] and neutron fluxes [2] as well as heat fluxes in the range of $0.3-2 \mathrm{MW} / \mathrm{m}^{2}$ [2-4]. To protect the structural steel of the first wall while still enabling heat transfer, a coating with tungsten represents a promising solution. Tungsten's has a high sputtering resistance [5], high melting temperature [6], high thermal conductivity [7] and low neutron activation [8]. The challenge of thermal expansion coefficient mismatch between tungsten and steel may be overcome by creating a functionally graded material (FGM) joint $[9,10]$, using thermal spraying techniques, such as vacuum plasma spraying (VPS) [11-13] or atmospheric plasma spraying [14,15]. Oxide formation can be avoided by using either vacuum or non-oxygen gas shrouding $[11,12,15]$. 
In previous optimisation steps, coatings with a total thickness of $2 \mathrm{~mm}$ were developed, consisting of $0.8 \mathrm{~mm}$ of tungsten top coat and $1.2 \mathrm{~mm}$ of functionally graded material with a linear gradient in tungsten content over five interlayers with $25,37,50,63$ and 75 vol\% tungsten $[11,12,16,17]$. The total coating thickness of $2 \mathrm{~mm}$ was chosen to match the value used in current design studies of First Wall elements [18-20]. It represents a compromise between high thickness required for heat shielding and low thickness required for sufficiently high tritium breeding ratio of the reactor [21,22]. The $1.2 \mathrm{~mm}$ thickness of the functionally graded material was found by means of finite element simulations to minimise creep strains and thus increase the allowed number of thermal cycles [9]. These coatings were recently proven to withstand fusion-relevant heat loads [16]: A helium-cooled mockup with such coatings was successfully tested in the HELOKA facility (Karlsruhe Institute of Technology, Germany), using 1000 cycles with an electron beam of $0.7 \mathrm{MW} / \mathrm{m}^{2}$ average heat flux density and with heating and cooling times of $180 \mathrm{~s}$ and $150 \mathrm{~s}$, respectively, during each cycle. The surface temperature of the coating remained below $800^{\circ} \mathrm{C}$, the substrate temperature below and mechanical properties of the substrate were not diminished after testing [16]. Additionally, smaller samples with similar coating were subjected to thermal shock tests in the JUDITH 1 facility (Forschungszentrum Jülich, Germany) to test the coating under transient heat loads comparable to edge localised modes, using 100 thermal shock pulses with a focussed electron beam, a single pulse duration of $1 \mathrm{~ms}$ and testing at base temperatures of both room temperature and $550^{\circ} \mathrm{C}$. The resulting thermal shock threshold of the coating was found between 0.19 and $0.38 \mathrm{GW} / \mathrm{m}^{2}$ for both base temperatures [23]. Furthermore, these coatings withstood 5000 thermal cycles between 300 and $550^{\circ} \mathrm{C}$, applied by alternating inductive heating and purge gas cooling, without showing signs of thermal fatigue [24]. Here we present a further development of these vacuum/low pressure plasma sprayed coatings. The aforementioned mock-up has reached the size limit (approx. 300x200 $\mathrm{mm}^{2}$ ) that could be coated on laboratory scale [16]. However, further upscaling with industrial manufacturers is required to coat the metresized breeding blanket modules designed for DEMO [2]. At the same time, the European Research Roadmap to the Realisation of Fusion Energy foresees a transfer of technological know-how to industrial companies in order to create an infrastructure for manufacturing parts for fusion power plants when needed $[2,25]$. To this end, we present the first results of such a technology transfer. Samples of three different sizes $\left(50 \times 50 \mathrm{~mm}^{2}, 300 \times 200 \mathrm{~mm}^{2}, 500 \times 250 \mathrm{~mm}^{2}\right)$ have been coated by low pressure plasma spraying (LPPS) to transfer the technological know-how of FGM production and to test the feasibility of coating larger plates, including a new upscaling record for this coating technology $\left(500 \times 250 \mathrm{~mm}^{2}\right)$. The total layer thickness of $2 \mathrm{~mm}$ and the linear chemical gradient over five interlayers have been maintained. This work presents a quality inspection of all sample sizes, including distortion analysis and ultrasonic testing for delamination. Furthermore, a microstructure analysis was conducted based on the $50 \times 50 \mathrm{~mm}^{2}$ samples. 


\section{Materials and methods}

\subsection{Substrate, powder and coating process}

Three sample sizes to be coated were prepared: Small sample blocks of $50 \times 50 \times 20 \mathrm{~mm}^{3}$ were chosen for the initial technology transfer and the microstructure analysis reported here. Medium-sized plates of $300 \times 200 \times 20 \mathrm{~mm}^{3}$ posed an intermediate milestone as their area resembles the largest area to which this coating technology was successfully applied in a laboratory [16]. Large plates of $500 \times 250 \times 20 \mathrm{~mm}^{3}$ were envisioned to achieve a further upscaling step towards the large areas to be coated for the breeding blanket of the DEMO fusion reactor [2,26-28].

The coatings were required to meet specifications equal to those of previous development steps $[11,12,16,17]$, i.e. a total coating thickness of $2 \mathrm{~mm}+-10 \%$, consisting of $0.8 \mathrm{~mm}$ of tungsten top coat and $1.2 \mathrm{~mm}$ of functionally graded material. The FGM was required to consist of five interlayers of $240 \mu \mathrm{m}$ thickness each and with respective tungsten contents of $25,37,50,63$ and 75 vol\%.

As substrate material, P92 steel (1.4901) was chosen rather than the reduced-activation ferritic-martensitic steel EUROFER97 envisioned for DEMO [26,29] because of the limited availability of EUROFER97 [30] and the large size of plates to be coated here. P92 is a ferritic-martensitic steel with a chemical composition close to that of EUROFER97 (Table 1) [31-34] and finds use in high-temperature-high-pressure scenarios of fossil power plants $[35,36]$ as well as in the construction of mock-ups for the DEMO reactor [30]. When compared to P91 steel, another frequently used substitute for EUROFER97, P92 shows improved mechanical performance, especially under creep conditions [36-38].

Table 1. Main elements (in wt\%) of P92 and EUROFER97 steels [31,33,34].

\begin{tabular}{lcccccccc}
\hline & $\mathrm{C}$ & $\mathrm{Cr}$ & $\mathrm{W}$ & $\mathrm{Mn}$ & $\mathrm{Mo}$ & $\mathrm{V}$ & $\mathrm{N}$ & Fe, others \\
\hline \hline P92 & $0.07-0.13$ & $8.5-9.5$ & $1.5-2.0$ & $0.3-0.6$ & $0.3-0.6$ & $0.15-0.25$ & $0.03-0.07$ & bal. \\
EUROFER97 & $0.09-0.12$ & $8.5-9.5$ & $1.0-1.2$ & $0.2-0.6$ & $<50 \mathrm{ppm}$ & $0.15-0.25$ & $0.015-0.045$ & bal. \\
\hline
\end{tabular}

The P92 substrates were manufactured from rolled sheet (thickness $50 \mathrm{~mm}$ ) by water jet cutting, sawing and milling. The workpieces underwent a heat treatment as specified in the P92 guidance [33]: Normalisation at $1090^{\circ} \mathrm{C}$ for 90 minutes, cooling to $170^{\circ} \mathrm{C}$ and holding for five minutes, then tempering at $760^{\circ} \mathrm{C}$ for 90 minutes, followed by cooling to room temperature. All heating cooling procedures were conducted at a rate of $5-10 \mathrm{~K} / \mathrm{min}$. Afterwards, oxide layers were removed by glass bead blasting and the workpieces were milled to their final dimensions and mock-up cooling channels were drilled in the $500 \times 250 \mathrm{~mm}^{2}$ and $300 \times 200 \mathrm{~mm}^{2}$ plates. In the back sides of the $50 \times 50 \mathrm{~mm}^{2}$, M8 holes were drilled as bearings for the coating process. The cooling channels in the plates were introduced with regard to future first wall panels, in order to investigate how the presence of cooling channels affects process heat management during coating as well as coating adhesion. Here, a simple cylindrical drill holes were selected as channels rather than the elaborated electric-discharge machining design for DEMO first wall panels $[3,27]$ because of the significantly reduced costs. 
The EUROFER powder used in the coating process was procured from the company NANOVAL GmbH \& Co. KG (Berlin, Germany). It was fabricated by spray aeration of a melt with argon as described in [16], followed by sieving to reduce the amount of fine particles to prevent the risks of clogging and metal fire. The mean particle diameter was $d_{50} \approx 29.8 \mu \mathrm{m}$. The tungsten powder (specified purity $>99.8 \mathrm{wt} \%$ excl. oxygen) was procured from Haines \& Maassen Metallhandelsgesellschaft mbH (Bonn, Germany) and had reduced particle size $\left(d_{20} \approx 19 \mu \mathrm{m}, d_{90} \approx 38 \mu \mathrm{m}\right)$ compared to the one used in [16] to reduce the amount of unmelted particles in the coating.

The coatings were manufactured by the company COATEC GmbH (Schlüchtern, Germany). In terms of the process, low pressure plasma spraying was applied instead of VPS because of availability and expertise provided by the partner. The applied pressure during LPPS (40 mbar), however, was similar to the pressures previously used (60-140 mbar) in vacuum plasma spraying [12]. The coating setup comprised two plasma guns, one for spraying, equipped with four powder feeders (two for tungsten, two for EUROFER) and a second gun for heat transfer optimisation. The plasma guns were operated with argon, with minor amounts of $\mathrm{He}$ and $\mathrm{H}_{2}$ as secondary gases for improved heat transfer. An overview of spraying parameters is provided in Table 2.

Table 2. Coating parameters used for low pressure plasma spraying.

\begin{tabular}{lccc}
\hline Substrate size $\left(\mathrm{mm}^{2}\right)$ & $50 \times 50$ & $300 \times 200$ & $500 \times 250$ \\
\hline \hline Current (A) & 1300 & 1300 & 1350 \\
Power (kW) & 84.5 & 84.1 & 84.2 \\
Voltage (V) & 65 & 64.7 & 62.4 \\
Primary gas Ar (SLPM) & 93 & 93 & 93 \\
Secondary gas He (SLPM) & 10 & 10 & 10 \\
Secondary gas H2 (SLPM) & 12 & 12.5 & 13 \\
Feed gas for EUROFER (SLPM) & 7 & 7 & 7 \\
Feed gas for tungsten (SLPM) & 9.2 & 9.2 & 9.2 \\
Chamber pressure (mbar) & 40 & 40 & 40 \\
Spraying distance (mm) & 300 & 300 & 300 \\
Traverse speed (m/min) & 7.5 & 7.5 & 7.5 \\
Substrate temperature $\left({ }^{\circ} \mathrm{C}\right)($ approx.) & $695-752$ & $727-758$ & $735-757$ (centre position) \\
& & & $677-730$ (corners) \\
\hline
\end{tabular}

117 The substrate temperature in Table 2 was surveyed on test samples during the development of optimised 118 coating parameters. The test samples were of size equal to that of the final samples and the thermocouples 119 used were placed in holes drilled from the back side of the parts. For the $500 \times 250 \mathrm{~mm}^{2}$ plates, temperature 120 was measured in the middle of the plate as well as in two opposite corners.

121 The powder feeding rates ranged from 18 to $67 \mathrm{~g} / \mathrm{min}$ for $\mathrm{W}$ and from 0 to $111 \mathrm{~g} / \mathrm{min}$ for EUROFER, 122 depending on the respective interlayer of the functionally graded material. The total powder usage was 
$60 \mathrm{~kg}$ of EUROFER (of $230 \mathrm{~kg}$ sent to manufacturer for cushion purposes) and $100 \mathrm{~kg}$ of tungsten powder 124 (of $450 \mathrm{~kg}$ sent to manufacturer).

125 In total, ten $50 \times 50 \mathrm{~mm}^{2}$ blocks, two $300 \times 200 \mathrm{~mm}^{2}$ plates and two $500 \times 250 \mathrm{~mm}^{2}$ plates were delivered with 126 coating (Figure 1). Specimens for a metallographic assessment of coating quality were cut from four of the 127 ten $50 \times 50 \mathrm{~mm}^{2}$ blocks by electric discharge machining and polished by standard metallographic means with $128 \varnothing 0.1 \mu \mathrm{m}$ diamond suspension as last step.

a
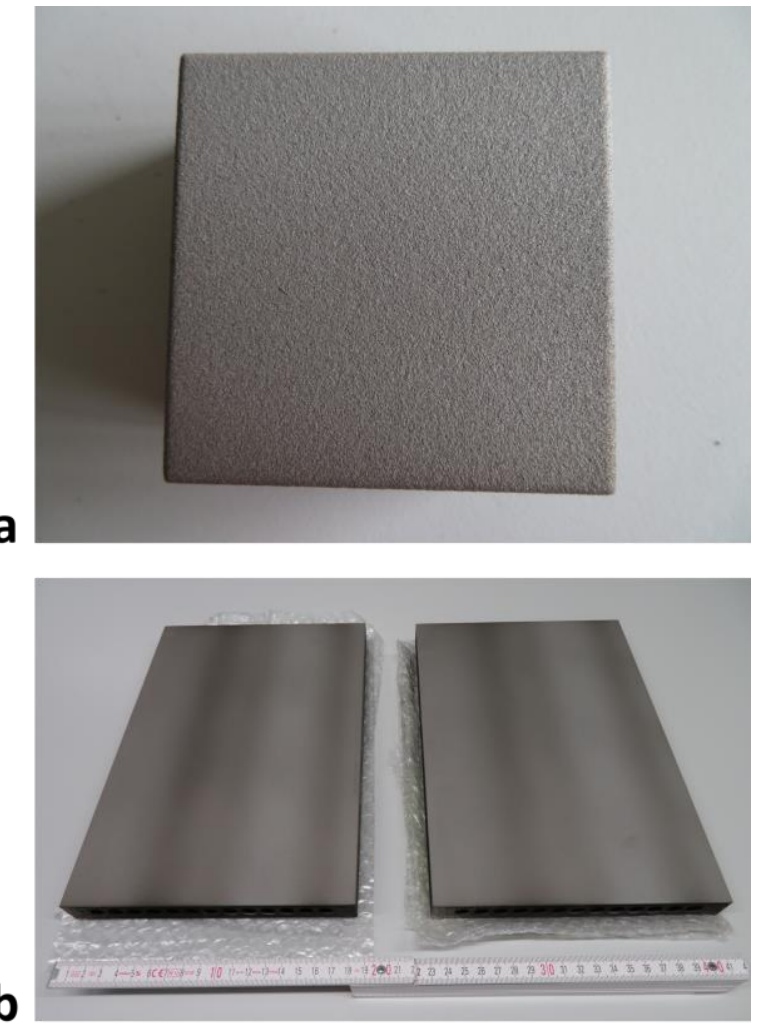

130 Figure 1. (single column image) (a) Close-up top view of the industrial coating on a $50 \times 50 \mathrm{~mm}^{2}$ block. (b) Industrycoated $300 \times 200 \mathrm{~mm}^{2}$ plates with cooling channels. (b) Industry-coated $500 \times 250 \mathrm{~mm}^{2}$ plate with cooling channels (right side) compared to largest laboratory-coated mock-up (left side). 
The total thickness of the coating was determined on as-cut samples by optical microscopy (VHX-1000 digital microscope, Keyence, Osaka, Japan). The coating-substrate interface was readily discernible even on unpolished samples. For the coating thickness, four $50 \times 50 \mathrm{~mm}^{2}$ substrates and six specimens per substrate were evaluated. For each specimen, 15 thickness measurements were taken over its width, giving a total of 360 evaluated thickness measurements. The thickness of the individual interlayers of the functionally graded (FG) coating was not easily distinguishable by optical microscopy. Instead, polished specimen prepared by standard metallographic procedures were investigated by scanning electron microscopy (SEM, EVO MA10, Zeiss, Oberkochen, Germany, equipped for energy-dispersive X-ray spectroscopy with XFlash detector 410-M, Bruker Nano GmbH, Berlin, Germany) for layer thickness as well as microstructure analysis. Here, one specimen from each of four investigated $50 \times 50 \mathrm{~mm}^{2}$ blocks was evaluated. For each specimen, three secondary electron images were taken with an acceleration voltage of $20 \mathrm{kV}$ and a working distance of $10 \mathrm{~mm}$. For each SEM image, three to five thickness measurements per interlayer were taken, giving a total of at least 36 thickness measurements per interlayer. The accuracy for correctly determining individual interfaces between layers is estimated to be in the same order of magnitude as the standard deviation of the measurements.

For elemental analysis by energy-dispersive X-ray spectroscopy (EDX), five pieces taken from four of the $50 \times 50 \mathrm{~mm}^{2}$ blocks were investigated, with a working distance of $13 \mathrm{~mm}$. For each coating layer an EDX multi point analysis covered $30 \times 30$ points distributed over an area of about $100 \times 100 \mu \mathrm{m}^{2}$.

\subsection{Thresholding analysis of porosity and W content}

A thresholding analysis of SEM cross sections was applied to quantify the porosity and tungsten content of the coatings. Five specimens were evaluated, taken from four different $50 \times 50 \mathrm{~mm}^{2}$ blocks, using the opensource software distribution Fiji / ImageJ [39]. For each specimen and each coating layer, three secondary electron images were evaluated. A magnification of $1060 \times$ allowed to cover representative views of each layer without the risk of imaging more than one interlayer simultaneously (image height approx. $200 \mu \mathrm{m}$, interlayer thickness approx. $240 \mu \mathrm{m}$ ). The porosity in each image was determined by thresholding analysis of its grey scale values, with pores corresponding to lowest grey scale levels, i.e. darkest pixels (Figure 2). Since none of the built-in thresholding algorithms in Fiji / ImageJ was able to identify the pores in a reliable way, the threshold was adjusted manually, following the practice described in ref. [40]: For each image, the grey scale value at which the frequency of occurrence starts to increase rapidly marks the onset of nonpore material. For the analysis of tungsten content, the grey scale threshold was set to separate W phase (highest grey scale values, see Figure $2 \mathrm{~d}$ ) from steel phase (medium grey scale) and pores (low grey scale). In this case, the standard thresholding algorithm of Fiji / ImageJ, the "isodata" algorithm [41], reliably identified the $\mathrm{W}$ phase. 
non-isotropic, flat shape (Figure 6b), the determined area percentages are merely an approximation of the real volume fractions.
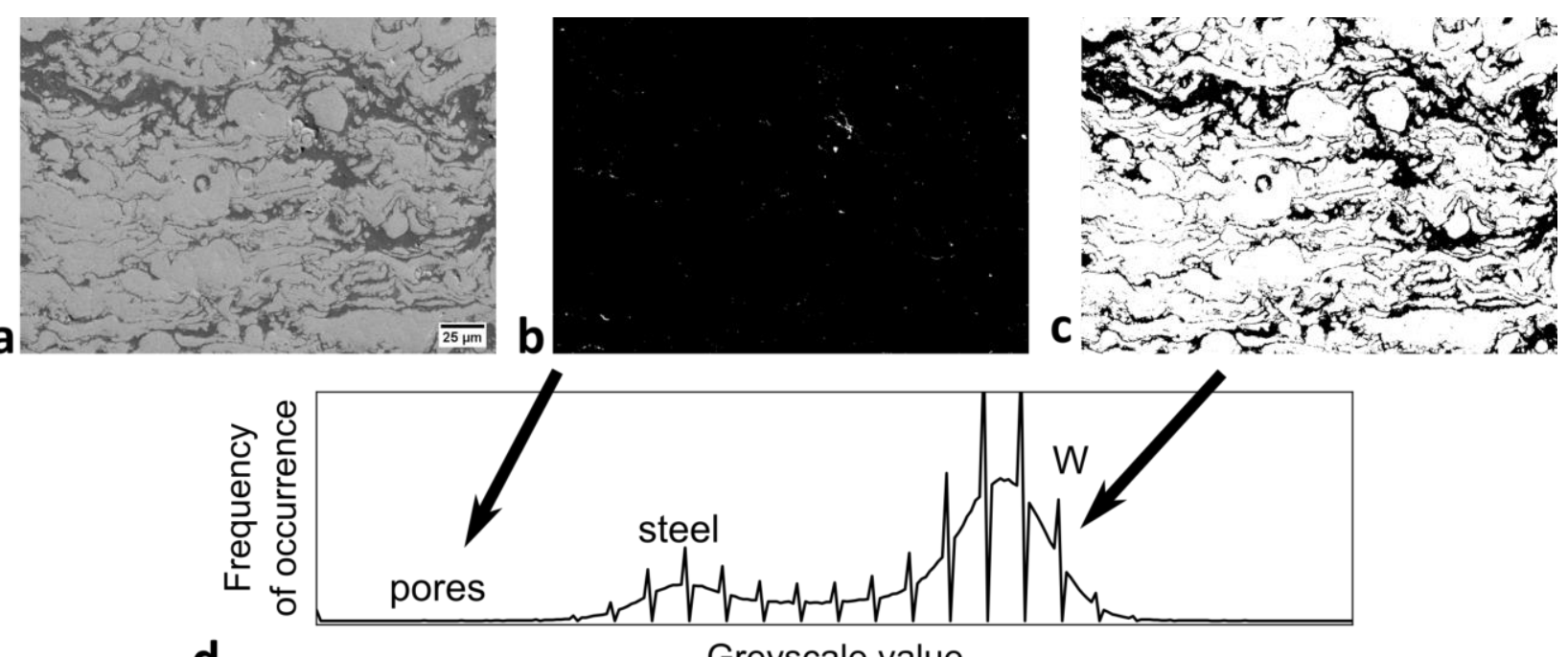

\section{d}

Greyscale value

Figure 2. (double column image) Thresholding analysis example: (d) shows the grey scale histogram for the input image (a). (b) Pores (here white) are isolated by selecting only the darkest grey scale values, left of the "steel" peak in (d). (c) Selecting the brightest grey scale values - the "W" peak in (d) - isolates the tungsten particles.

\subsection{Ultrasonic immersion analysis}

All received samples were investigated by ultrasonic immersion analysis in water to search for potential delamination of the coating.

The facility used was a KC 200 Immersion testing facility, equipped with USIP40 testing device and KScan evaluation software (GE Inspection Technologies, Hürth, Germany) as described in [42]. A $10 \mathrm{MHz}$ ultrasonic probe was used and all analyses were conducted under $90^{\circ}$ angle of incidence with longitudinal sound waves. Data were evaluated either in the form of A-scans (1D plots of echo amplitude versus location of echo source under the surface) or C-scans (2D compilation of A-scan amplitude information for a sample area within a pre-selected depth). To compute the location of an echo source from the sound impulse run time, a sound velocity needs to be provided to the system. For inhomogeneous materials such as FGM, the calculated depth locations may therefore differ slightly from real positions, which is of no importance when searching for delamination though. When the coated front side pointed towards the probe, an averaged sound velocity of $5416 \mathrm{~m} / \mathrm{s}$ was chosen for the functionally graded coating as the result of averaging the sound velocities of EUROFER97 $(5920 \mathrm{~m} / \mathrm{s})$ [42] and tungsten $(5200 \mathrm{~m} / \mathrm{s})$ [16,43], weighted by their respective volume fractions of the coating. For measurements with the uncoated back side pointing upwards towards the probe, the sound velocity of P92 steel $(5775 \mathrm{~m} / \mathrm{s})$ was taken $[35,44]$. 


\section{Results and discussion}

\subsection{Visual inspection and distortion analysis}

The industrial coatings showed good homogeneity upon first visual inspection (Figure 1a). A darker colour as seen in stripes on all four larger plates partially coincided with a slightly increased roughness and is attributed to unmelted $\mathrm{W}$ particles on the surface. Even so, the visible surface roughness of all industry coatings was lower than the roughness of previous laboratory-produced coatings $[11,12,16]$.

A potential side effect of thermal spraying is the distortion of coated parts, occurring during cooling of the coating. This effect tends to be more severe for larger parts and therefore requires attention during development of coatings for the breeding blanket. A distortion analysis of the $300 \times 200 \mathrm{~mm}^{2}$ and $500 \times 250 \mathrm{~mm}^{2}$ plates was conducted at the company topometric $\mathrm{GmbH}$ (Göppingen, Germany). For each of the four plates, a 3D image of the uncoated back side was measured by optical triangulation to find aberrations from the ideal surface. Additionally, this company has conducted a roughness analysis of the coating of one of the $500 \times 250 \mathrm{~mm}^{2}$ plates.

The distortion analysis revealed small but clear warping of all plates after coating. An example for a $500 \times 250 \mathrm{~mm}^{2}$ plate is shown in Figure 3c. The corners of the uncoated back sides all have moved downwards (red colour in Figure 3c) while the plate centres have moved upwards (blue colour in Figure 3c). This can be explained by the larger coefficient of thermal expansion of the steel substrate when compared to the tungsten [9]. As the coating shrinks less upon cooling, it locally hinders a uniform shrinkage of the plate, resulting in warping of the plate with corners pressing downwards. Quantitatively, however, this warping is small. The maximum height difference between corners and centre (approx. $0.4 \mathrm{~mm}$ for the $300 \times 200 \mathrm{~mm}^{2}$ plates and $0.6 \mathrm{~mm}$ for the $500 \times 250 \mathrm{~mm}^{2}$ plates) is of the same order of magnitude as the tolerance for planarity applied during manufacturing of the substrate plates.

On the other hand, the deviation of the side faces from ideal geometry indicates a shrinkage of all plates within the substrate plane. An example for a $500 \times 250 \mathrm{~mm}^{2}$ plate is shown in Figure 3a. This deviation is in the order of $1-2 \mathrm{~mm}$, regardless of the plate size, and thus is, in the worst case, in the order of $0.4-1 \%$ of the respective length dimensions. It is considered small but not negligible with future upscaling in mind. The order of magnitude of distortion, both in warping and shrinkage, is in agreement with the one found with previous finite element simulations of coated plates with comparable size [45].

The roughness analysis of the coated front side (Figure 3a,b) revealed only minor height deviations, mostly within the specified coating thickness of $2 \mathrm{~mm} \pm 10 \%$.

The $2 \mathrm{~mm}$ offset in Figure 3 a results from comparing the $2 \mathrm{~mm}$ thick coating with the CAD model of an uncoated plate. Lowest surface heights were found at two opposite plate ends (blue colour in Figure $3 b$ ). The reduced height of about $0.3 \mathrm{~mm}$ at these two ends roughly coincides with the downwards warpage found during measurement of the back side and is thus regarded as another sign of the warpage, rather than actual reduction of coating thickness. Peak roughness of about $0.3 \mathrm{~mm}$ above rest of the surface (red colour in Figure $3 b$ ) was found in the middle of the plate and in the middle of one stripe at the lower end, 
the middle position in line with the upwards movement caused by warpage. This peak roughness is not [46]. While the stripe in Figure 3b coincides with a dark stripe found during visual inspection, other dark 230 stripes had no obvious counterpart in the roughness analysis.
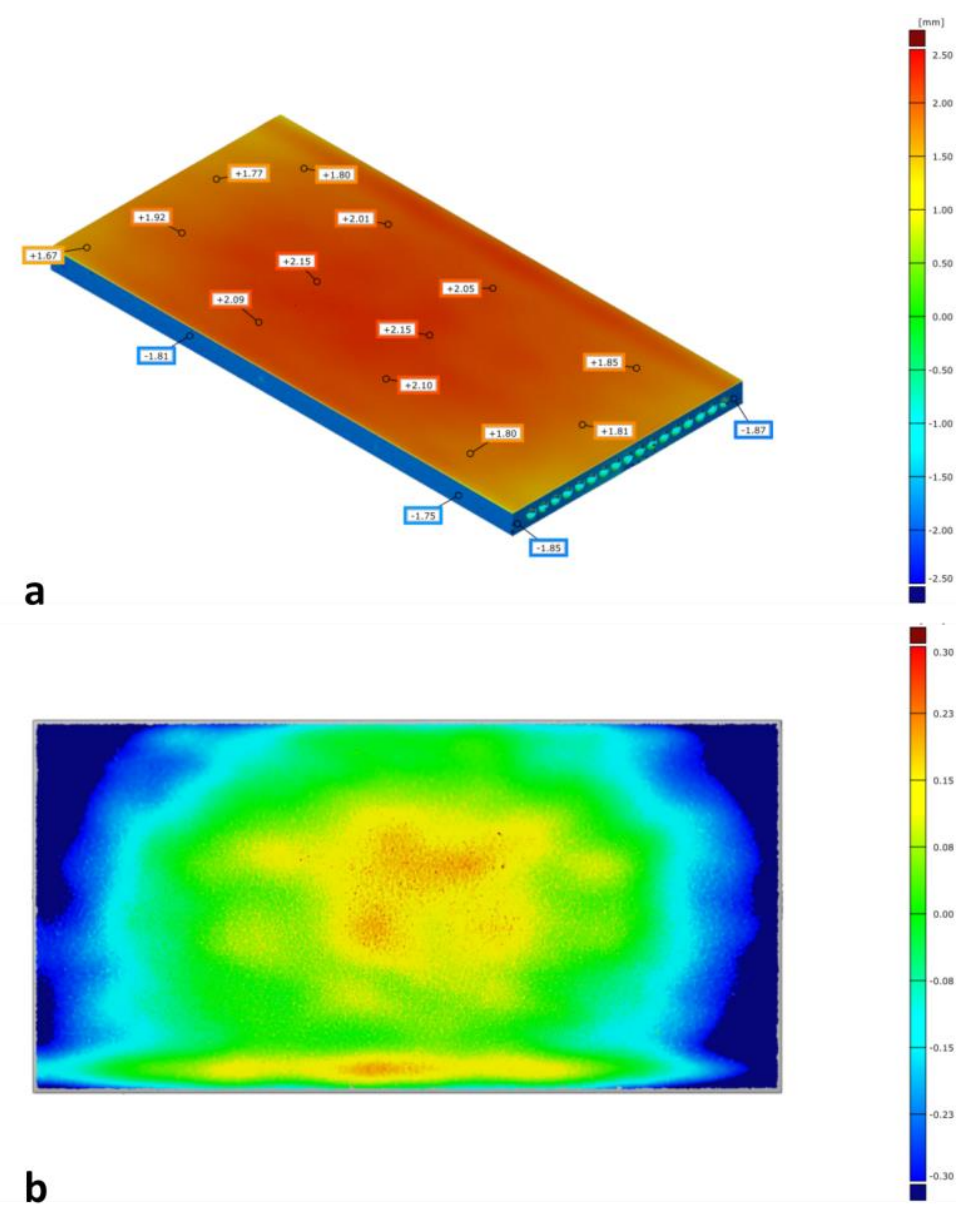

b

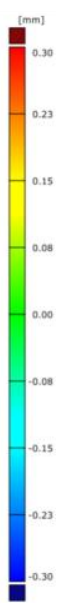

Figure 3. (single column image) Distortion and roughness analysis for $500 \times 250 \mathrm{~mm}^{2}$ plates, conducted by topometric $\mathrm{GmbH}$. (a) Deviations of front and side faces from ideal position. The $2 \mathrm{~mm}$ offset of the front face is the target thickness of the coating. (b) Height profile of the coated front side. (c) Warpage of the back side. (a) and (b) refer to the same plate while (c) shows a different plate that displayed the largest warping. 


\subsection{Thickness of coating and interlayers}

237 A visualisation of the mean thickness values is shown in Figure 4a. Error bars show the standard deviation 238 of thickness for the entire coating and the five FGM interlayers. Figure $4 b$ shows a SEM cross section of the coating for comparison. The total coating thickness of the samples met the targeted value of $2 \mathrm{~mm} \pm 10 \%$. The coating always was slightly thicker than $2 \mathrm{~mm}$ because of increased thickness of the $\mathrm{W}$ top layer (approx. $900 \mu \mathrm{m}$ instead of $800 \mu \mathrm{m}$ ). The average thickness of the five FG interlayers met the targeted $242240 \mu \mathrm{m}$ for all interlayers, within a margin of $\pm 10 \%$.

243

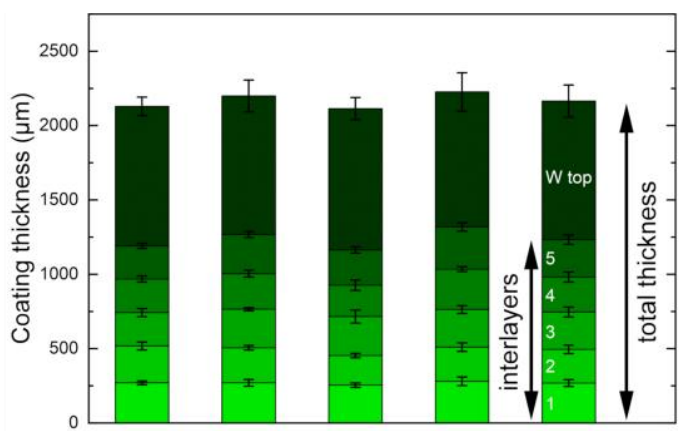

\section{a}

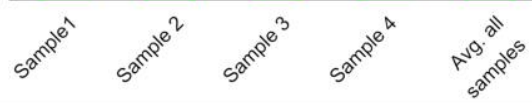

b

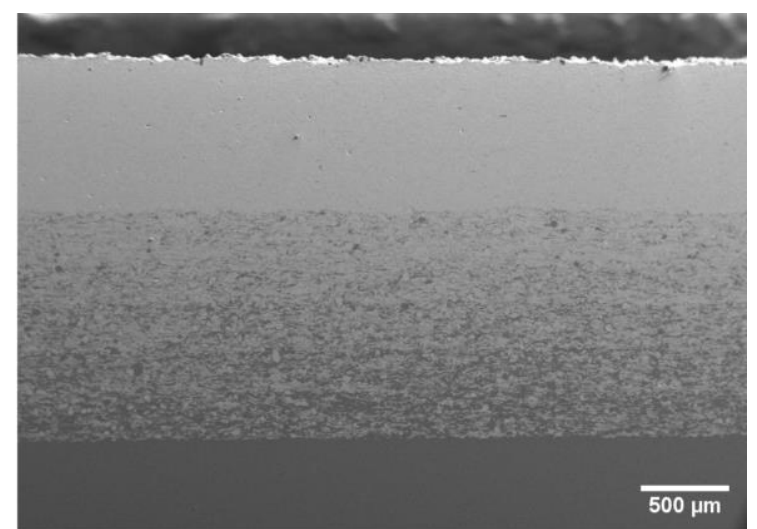

245 Figure 4. (double column image) (a) Layer thickness of four $50 \times 50 \mathrm{~mm}^{2}$ samples. (b) SEM BSE image of a coating 246 cross section.

\section{$247 \quad 3.3$ Coating microstructure}

248 The SEM analysis of the $50 \times 50 \mathrm{~mm}^{2}$ blocks showed a microstructure built by stacking of "pancake shaped 249 particles", as is typical for plasma sprayed coatings. Typical SEM cross sections are shown in Figure 5. The 250 pancake shaped particles measured about 5-10 $\mu \mathrm{m}$ in thickness and 30-60 $\mu \mathrm{m}$ in diameter. Occasionally, 251 round tungsten particles with a diameter of about 30-50 $\mu \mathrm{m}$, which did not melt during the coating process, were also found (Figure 5a). Both particle types are highlighted in Figure 5b. This microstructure resembles the one of the previous, laboratory-produced coatings $[11,17]$. 

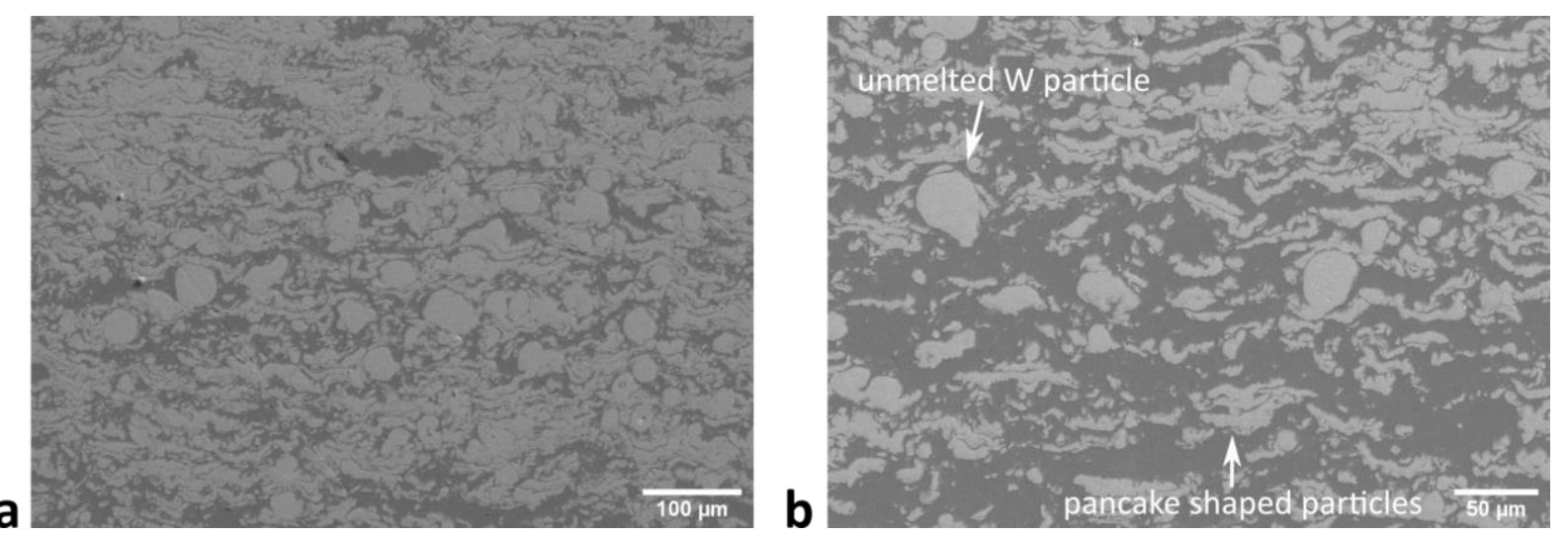

255 Figure 5. (double column image) SEM cross sections of the coating showing a typical microstructure of stacked, pancake 256 shaped particles. Larger, round particles as visible in the middle of (a) and highlighted in (b) are unmelted tungsten 257 particles.

258 The interface between coating and substrate (Figure 6a) appears like a sudden onset of tungsten particles 259 within a steel matrix upon magnification (Figure 6b), with the coating steel particles being indistinguishable 260 from the steel substrate. This indicates the establishment of metallic bonding to the substrate, as found 261 previously for laboratory-produced coatings [45,47]. Interface pores as well as interparticle pores within the 262 coating (Figure 6b) were found only in minor amounts. A quantitative assessment of bond strength at the 263 interface will be subject to future study. The interface between FGM and W top layer has a similar 264 appearance as the interface to the substrate (Figure $6 \mathrm{c}, \mathrm{d}$ ) and shows almost no porosity. Within the W top 265 layer, boundaries between single W particles are occasionally visible (top of Figure 6d). They presumably 266 represent minor porosity or stem from leftover steel feedstock, since oxide layers, as a potential alternative 267 [14], are unlikely to form during the vacuum process. 

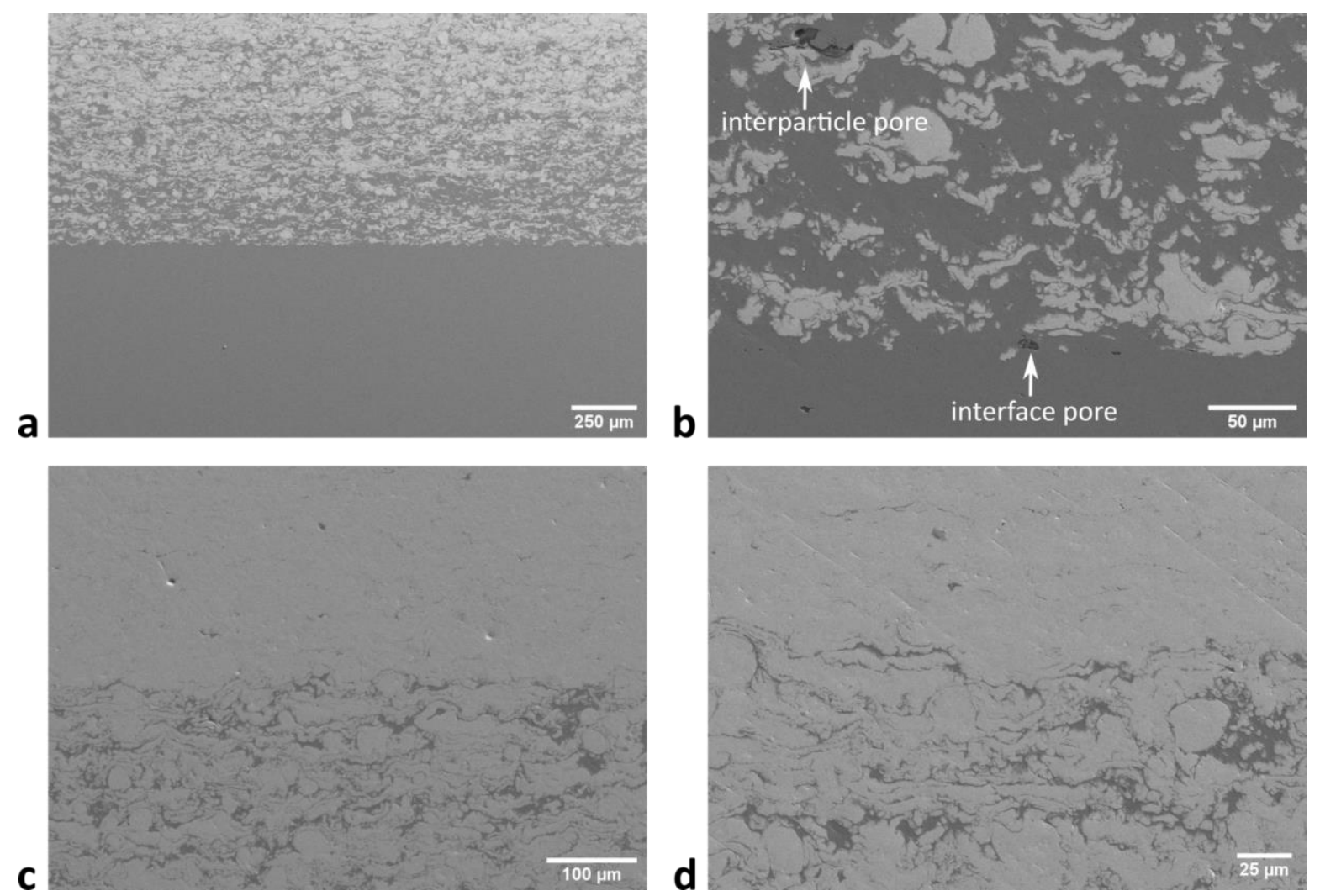

Figure 6. (double column image) SEM cross section of the interfaces between $(a, b)$ coating and substrate and $(c, d) W$ top layer and FGM. (b,d) show magnified views. Minor porosity is highlighted in (b).

\section{$271 \quad 3.4$ Porosity and chemical gradation}

272 Porosity may influence mechanical and thermal properties $[48,49]$ of the coatings as well as their hydrogen 273 permeability [50].

274 The porosity of each coating layer, estimated by thresholding analysis, is listed in Table 3 and was found to 275 be approximately $0.1 \%$ for the $F G$ interlayers and $0.5 \%$ for the $\mathrm{W}$ top layer. These values are very low 276 when compared to the porosities of $1-5 \%$ found in the laboratory-produced coating [17]. Although this could 277 indicate a high coating quality, the porosity of plasma sprayed coatings more typically is in the range of 278 several percent [48]. Therefore, the porosity values should be treated with caution. The pores of the cross 279 sections may potentially be clogged with material from metallographic preparation that was not sufficiently 280 removed. However, thorough ultrasonication did not reveal additional pores. We note though that an earlier 281 study of plasma-sprayed tungsten (without FGM) has found a similarly low porosity of $0.6 \%$ [49]. 
Table 3. Porosity and W content from image thresholding analysis.

\begin{tabular}{ccccc}
\hline Coating layer & \multicolumn{2}{c}{$\begin{array}{c}\text { porosity } \\
\text { (area\%) }\end{array}$} & $\begin{array}{c}\text { W content } \\
\text { (area\%) }\end{array}$ \\
\hline \hline total & $0.17 \pm 0.19$ & \multicolumn{2}{c}{-} & \\
\hline W top layer & $0.51 \pm 0.22$ & & - & \\
interlayer 5 & $0.12 \pm 0.07$ & $80.6 \pm$ & 2.2 \\
interlayer 4 & $0.10 \pm 0.07$ & $71.6 \pm 2.7$ \\
interlayer 3 & $0.08 \pm 0.06$ & $60.3 \pm 2.7$ \\
interlayer 2 & $0.08 \pm 0.05$ & $47.8 \pm 4.9$ \\
interlayer 1 & $0.12 \pm 0.14$ & $33.6 \pm 4.0$ \\
\hline
\end{tabular}

In order to evaluate the tungsten content of the FG coating's interlayers, energy-dispersive X-ray spectroscopy (EDX) was compared with a thresholding analysis. The thresholding results are listed in Table 3 while the EDX results are visualised in Figure 7a. Figure 7b shows an EDX map of the coating's iron content which confirms and visualises the chemical gradation of the coating. According to EDX results, the tungsten content of the two uppermost interlayers (4 and 5) meets the target value while in the lower three interlayers ( 1 to 3 ) the $\mathrm{W}$ content is about 4 to 7 vol\% too low. This is a good result considering the imprecise nature of the coating process where $\mathrm{W}$ and steel powders have to be provided to the spray gun by different feeders.

The tungsten content as found by thresholding analysis exceeded the target value by 6 to $11 \%$ per layer. This may be explained by the challenge of a $2 \mathrm{D}$ slicing analysis of 3D objects and the irregular shape of $\mathrm{W}$ particles. The EDX results are considered more reliable. However, both approaches independently confirmed the chemical gradation of the FG coating.
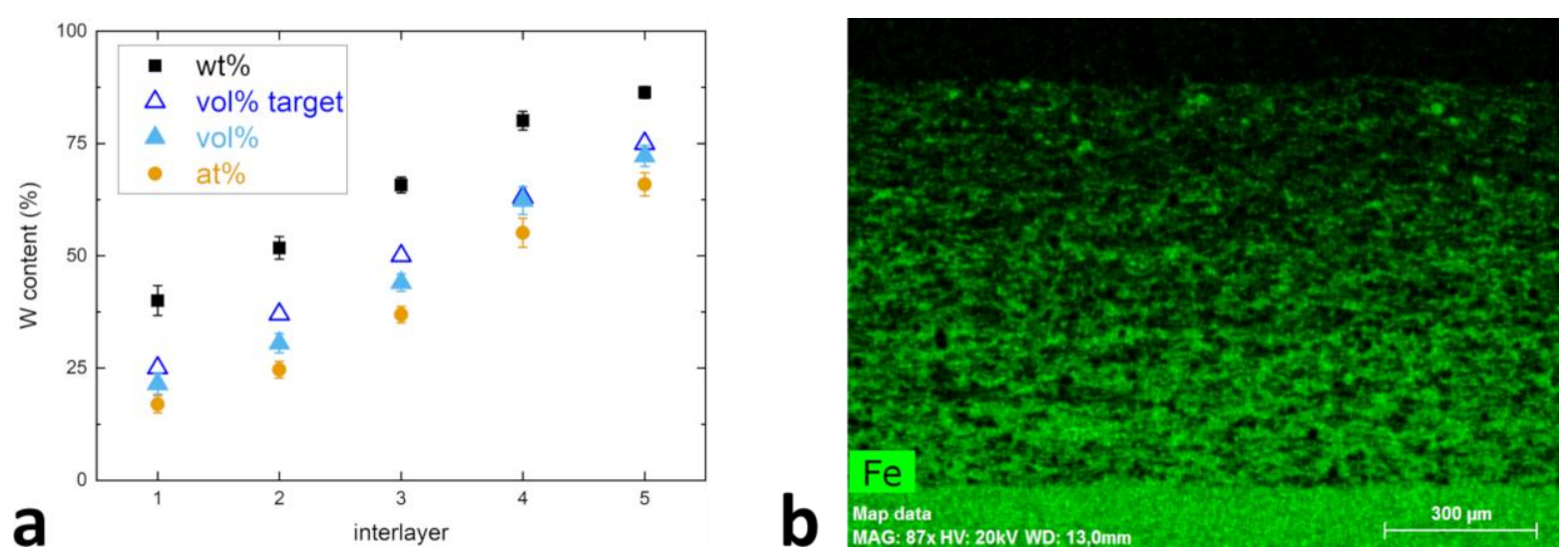

Figure 7. (double column image) EDX analysis of the five FG coating interlayers. (a) Tungsten content of the interlayers.

(b) EDX map showing iron content (green) increasing from the $W$ top layer (black, top) towards the substrate (bottom).

\subsection{Ultrasonic immersion analysis}

300 Each sample was investigated by ultrasonic analysis. In short, no delamination was detected. However, inspection of the larger plates provided hints to potential weak spots in the corners. This section presents the results from one ultrasonic analysis per sample size (Figures 8-10). 
Figure 8 shows the results for a $50 \times 50 \mathrm{~mm}^{2}$ block, displaying C-scans of the accumulated signal for the regions at 2-4, 4-6 and 22-24 mm below the coating surface. Deviations from sample thickness $(20 \mathrm{~mm}+$ $2 \mathrm{~mm}$ coating) arise from using averaged sound velocity.

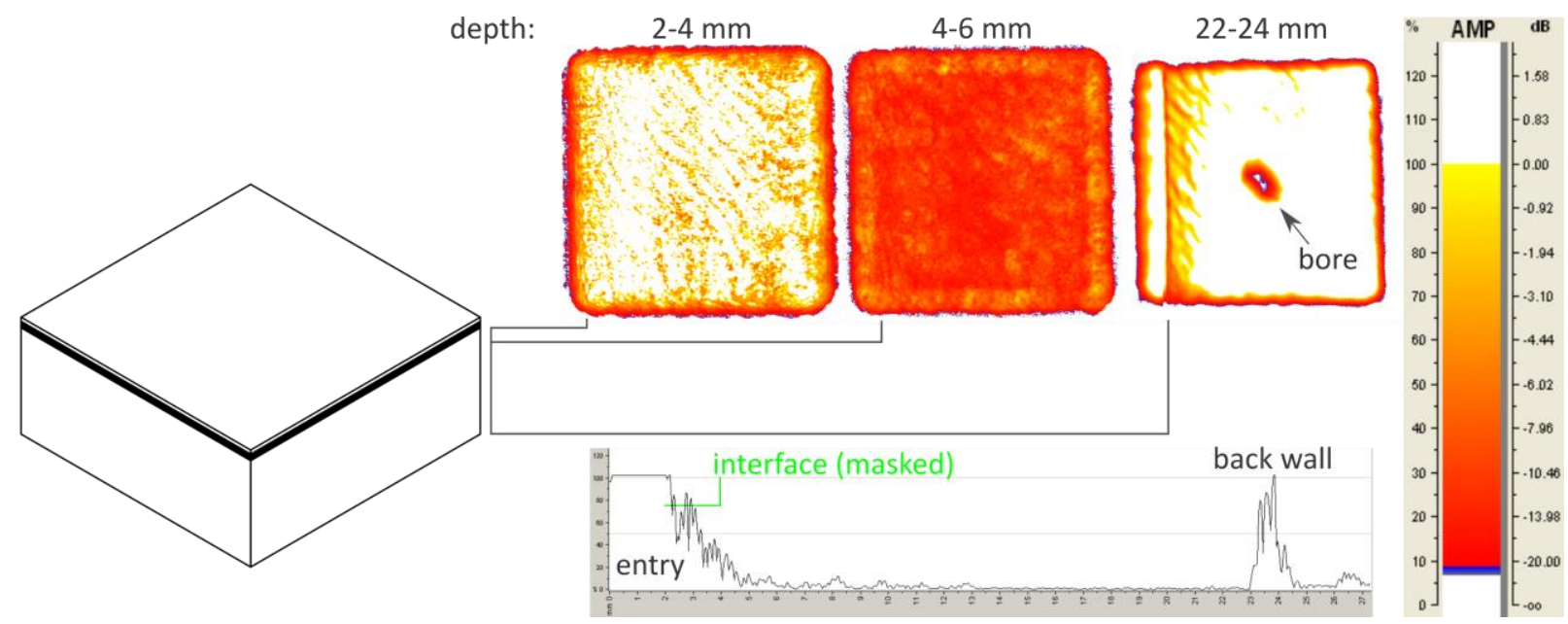

Figure 8. (double column image) Ultrasonic analysis of $50 \times 50 \mathrm{~mm}^{2}$ block showing C-scans (top) from three different depths (2-4, 4-6 and 22-24 mm below coating surface) and an A-scan (bottom) displaying typical entry and back wall echos. C-scan colour displays signal amplitude. The A-scan does not clearly show the echo from the coating-substrate interface since it overlaps with the entry echo. $C$-scans for 2-4 and 4-6 mm depth show homogeneous distribution and signal decay of the entry echo. The $C$-scan for 22-24 mm depth displays evenly distributed back wall echo except for a bore in the middle.

The coating-substrate interface at $2 \mathrm{~mm}$ depth is not clearly discernible from individual A-scans (Figure 8 bottom), as it is masked by a broad entry echo. However, the C-scans for 2-4 and 4-6 mm depth show homogeneous distribution of the entry echo as well as an evenly distributed signal decay towards greater depths. This indicates good adhesion of the coating over the entire block. The same conclusion may be drawn from the homogeneous back wall echo in the C-scan at 22-24 mm depth. Any inhomogeneity here would suggest masking by defects above, but was only found for the bore in the middle of the block. The distinct, vertical line at the left edge at $22-24 \mathrm{~mm}$ depth and the round edges in all C-scans are artefacts from the ultrasound passing the sample edges. 


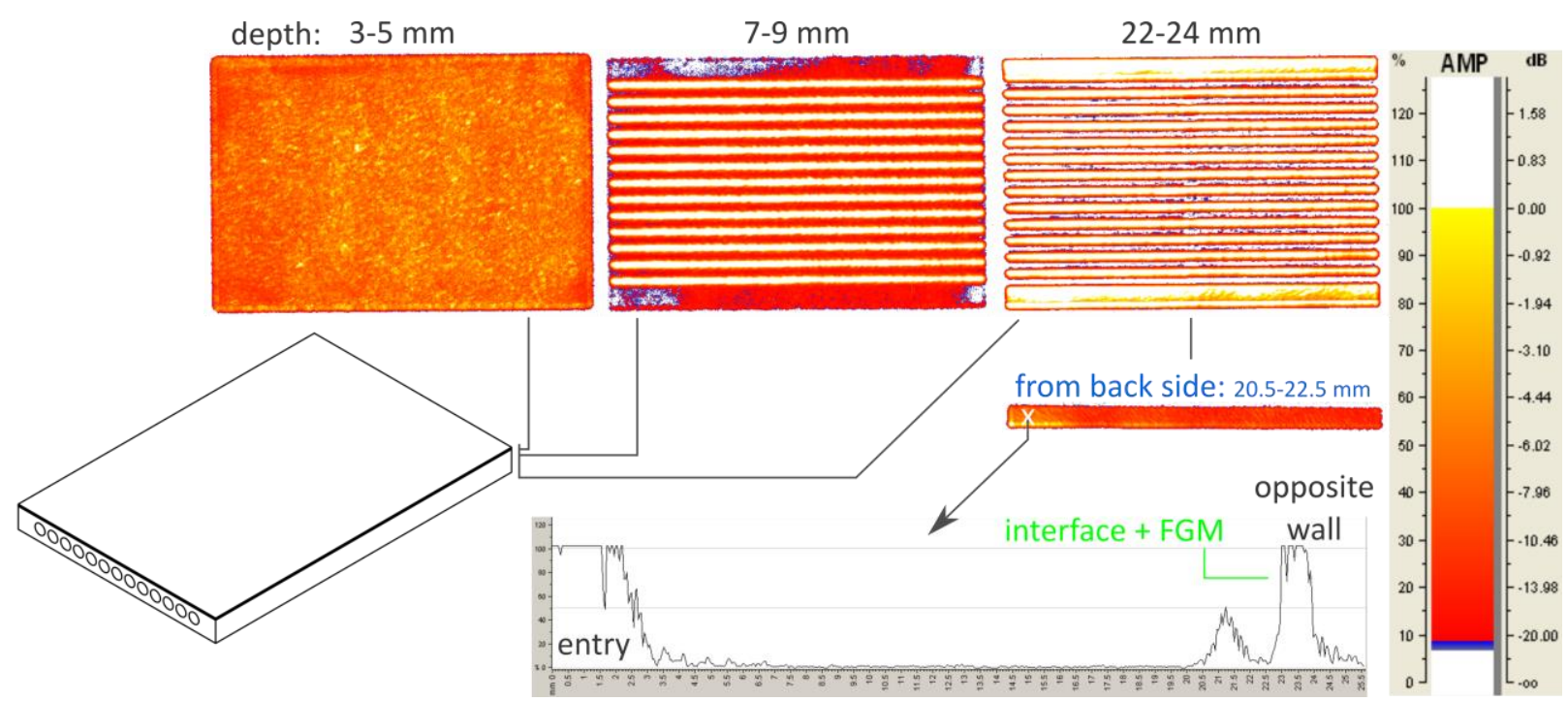

Figure 9. (double column image) Ultrasonic analysis of $300 \times 200 \mathrm{~mm}^{2}$ plate showing $C$-scans (top) from three different depths (3-5, 7-9 and 22-24 mm below coating surface). C-scan colour displays signal amplitude. The C-scan for 3-5 mm depth shows homogeneous decay of entry echo except for some regions on the edges with weaker signal that become more visible at 7-9 mm depth, along with the bores. At 22-24 $\mathrm{mm}$ depth, the back wall echo is visible everywhere except behind the bores, but is not completely homogeneous at the edges. The additional narrow $C$-scan shows the lower edge measured from the back side and focussed to the depth where the interface+FGM signal is expected, as indicated in the adjacent $A$-scan (bottom).

The ultrasonic analysis of the $300 \times 200 \mathrm{~mm}^{2}$ plates, too, indicates coating adhesion over the entire area. Here, however, the adhesion may potentially be weaker at the edges. Figure 9 shows the results for one of the two plates. The displayed C-scans in the top line show the accumulated signal for the regions at 3-5, 79 and 22-24 mm below the coating surface. Additionally, a C-scan of one sample edge, measured from the back side instead of the coated front side is shown (Figure 9 bottom). The C-scan for 3-5 mm depth shows homogeneous decay of the entry echo except for some regions on the edges. These regions have a weaker signal, i.e. a locally enhanced decay of the entry echo, and become more visible at 7-9 mm depth. Here, also the bores become clearly visible. At $22-24 \mathrm{~mm}$ depth, the back wall echo is visible everywhere except behind the bores, suggesting that no delamination occurred at the edges since that would otherwise mask the back wall echo. However, the back wall echo is not evenly distributed along the edges. If no delamination occurred, this uneven distribution could be interpreted as differences in adhesion strength along the edges. While echos from FGM and coating-substrate interface are masked in scans of the coated front side, they are clearly visible when measuring from the back side. In Figure 9, the narrow C-scan of the sample edge measured from the back side is focussed on the depth region 20.5-22.5 mm behind the back wall, i.e. where the interface and FGM echos were found. The $0.5 \mathrm{~mm}$ offset here may be caused by difficulties of finding the zero in the broad entry echo or by deviation of the used sound velocity. This back side C-scan, like the ones taken from the front side, shows inhomogeneous signal amplitude along the sample edge. Apparently, the interface echo is stronger in certain regions. For one of these regions (marked by the white $\mathrm{X}$ in Figure 9) the corresponding A-scan is displayed (Figure 9 bottom). This A-scan reveals an echo in the region of 
coating-substrate interface and FGM. Behind this echo, the "opposite wall" echo (here stemming from the coating surface) is at full amplitude, indicating that no delamination occurred. As stated above, the uneven distribution of the FGM echo may be caused by local variation of adhesion strength. Alternatively, the local amplitude variation along the sample edge could also be caused by locally increased porosity within the FGM, higher amounts of unmelted particles or other inhomogeneities that interfered with the ultrasonic impulses. Also, the amplitude variation in the corners may be partially caused by the slight bending of the plates (Figure 3), since the ultrasonic analysis assumes a fixed zero position.

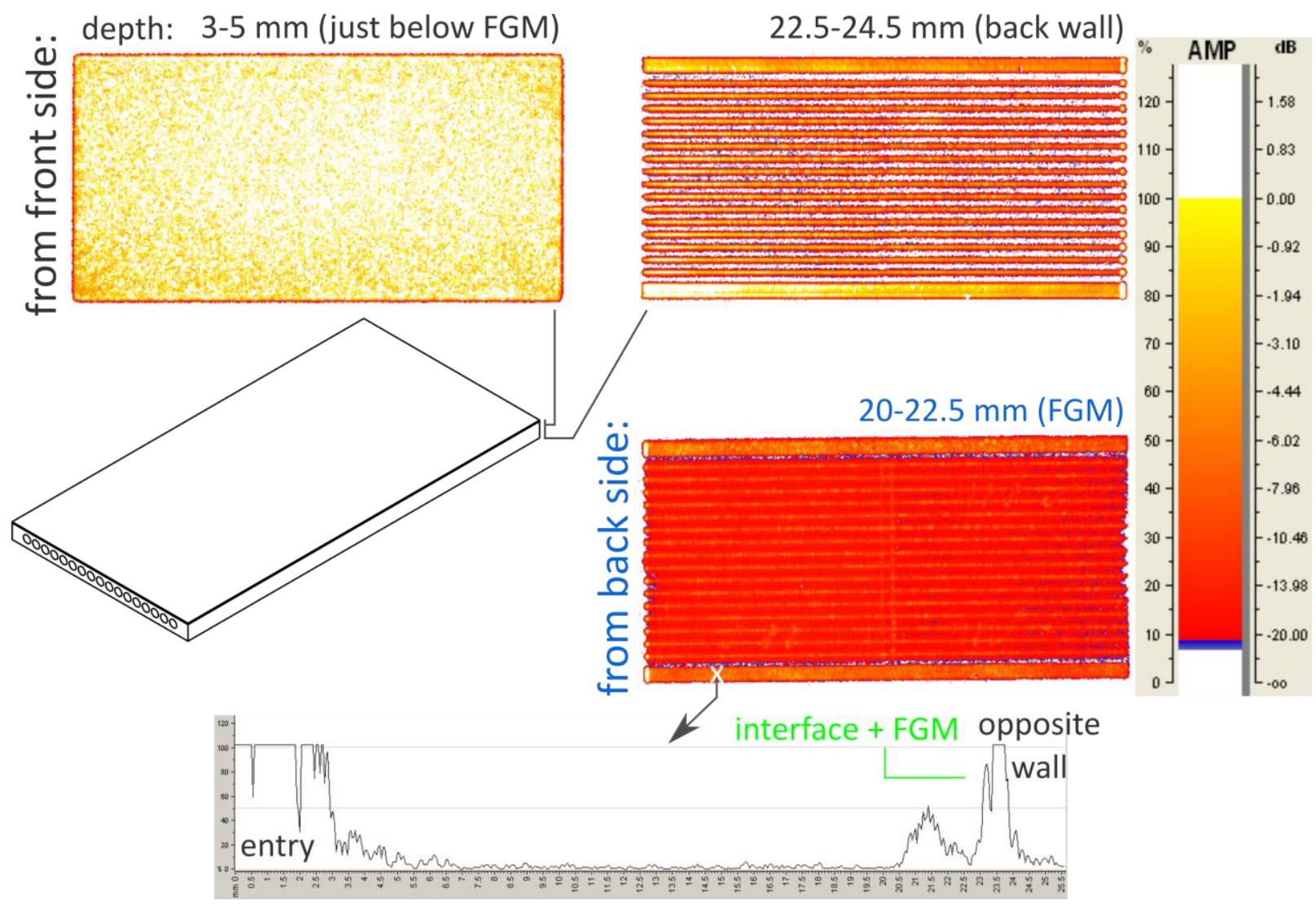

Figure 10. (double column image) Ultrasonic analysis of $500 \times 250 \mathrm{~mm}^{2}$ plate, showing two $C$-scans measured from the front side (top line, 3-5 and 22.5-24.5 mm below coating surface) and one C-scan measured from the back side (middle). $C$-scan colour displays signal amplitude. The $C$-scan for 3-5 mm depth shows homogeneous decay of entry echo except for corner regions. At 22.5-24.5 mm depth, the back wall echo is visible everywhere except behind the bores. Gradient of back wall echo from lower left to upper right corner is caused by uneven positioning of plate. The C-scan measured from the back side is focussed to the depth where the interface+FGM signal is expected (20-22.5 mm), as indicated in the adjacent A-scan. The echo from interface+FGM does not show interruptions except for where it is masked by the bores.

The ultrasonic analysis of the $500 \times 250 \mathrm{~mm}^{2}$ plates revealed a coating quality similar to the one found for the $300 \times 200 \mathrm{~mm}^{2}$ plates. As displayed in Figure 10 for one of the two plates, when measured from the front side, the entry echo showed a homogeneous decay over the entire sample area, except for a slightly stronger decay in the corners (top left C-scan of Figure 10, focussed at depth $3-5 \mathrm{~mm}$ below coating surface). A back wall echo was found over the entire plate area except for where it was masked by the bores 
(top right C-scan of Figure 10, focussed at depth 22.5-24.5 mm below coating surface). Therefore, a coating delamination can be excluded for all areas without bores. An apparent intensity gradient of the back wall echo from lower left to upper right corner of the plate is assigned to a slightly uneven positioning of the plate inside the ultrasonic bath. The assumption of homogeneous coating adhesion is supported by a measurement from the back side of the plate (C-scan in middle of Figure 10), which covers a depth 20$22.5 \mathrm{~mm}$ from the back side, i.e. where the FGM and the coating-substrate interface are expected. Their echo is evenly distributed over the plate area, except for where it is masked by the bores. The A-scan at the bottom of Figure 10 (taken on the edge position marked by a white $\mathrm{X}$ in the back side $\mathrm{C}$-scan) shows the echo from FGM and coating-substrate interface. Behind this echo, the "opposite wall" echo (coating surface) is at full amplitude, indicating that no delamination occurred. In contrast to the $300 \times 200 \mathrm{~mm}^{2}$ plate in Figure 9, the back side measurement in Figure 10 did not reveal an increased FGM echo in the corners, where the front side measurement showed stronger signal decay. Therefore, whether or not the coating is weakened in the corners remains unclear from this ultrasonic analysis. The second $500 \times 250 \mathrm{~mm}^{2}$ plate (not depicted here) showed a completely homogeneous coating, without irregularities on edges or corners. Potentially, the coating adhesion of the $500 \times 250 \mathrm{~mm}^{2}$ plates may therefore be stronger than for the $300 \times 200 \mathrm{~mm}^{2}$ plates. A mechanical investigation is planned.

\section{Conclusions}

This work reports first results on a transfer of W/EUROFER FGM coating technology to industry with regard to upscaling for future fusion first wall application. Samples of three different sizes, the largest with an area of $500 \times 250 \mathrm{~mm}^{2}$, have successfully been coated using low pressure plasma spraying. The specified coating thickness of $2 \mathrm{~mm}$ was met, including $0.8 \mathrm{~mm}$ of tungsten top layer and $1.2 \mathrm{~mm}$ of functionally graded material. The distortion of the larger samples was quantified, with warping remaining within the plate's manufacturing tolerances. Chemical gradation was verified by EDX as well as image thresholding analysis, the latter also indicating low porosity. The coating's microstructure consisted of a dense packing of splatshaped particles of W and EUROFER, as is typical for plasma spraying, with minor amounts of unmelted particles and pores. Neither SEM nor ultrasonic analysis showed delamination at the coating substrate interface. However, the ultrasonic analysis revealed potential weaker spots at the corners of the large samples which will be subject to a future mechanical analysis, along with further microstructural analysis of the larger plates. Taken together, the transfer of W/EUROFER FGM technology to industry was successful with tests so far indicating an overall good coating quality. Further investigations envisioned include thermal fatigue tests, experiments under fusion-relevant heat loads including plasma exposure, and the characterisation of thermo-mechanical properties of single interlayers within the functionally graded material.

\section{Conflicts of interest}

There are no conflicts of interest to declare. 


\section{Acknowledgements}

This work has been carried out within the framework of the EUROfusion Consortium and has received funding from the Euratom research and training programme 2014-2018 and 2019-2020 under grant agreement No 633053. The views and opinions expressed herein do not necessarily reflect those of the European Commission.

\section{References}

[1] K. Ehrlich, The development of structural materials for fusion reactors, Philosophical Transactions of the Royal Society A - Mathematical, Physical \& Engineering Sciences. 357 (1999) 595-617. doi:10.1098/rsta.1999.0343.

[2] F.A. Hernández, P. Pereslavtsev, G. Zhou, Q. Kang, S. D’Amico, H. Neuberger, L.V. Boccaccini, B. Kiss, G. Nádasi, L. Maqueda, I. Cristescu, I. Moscato, I. Ricapito, F. Cismondi, Consolidated design of the HCPB Breeding Blanket for the pre-Conceptual Design Phase of the EU DEMO and harmonization with the ITER HCPB TBM program, Fusion Engineering and Design. 157 (2020) 111614. doi:10.1016/j.fusengdes.2020.111614.

[3] F.A. Hernández, F. Arbeiter, L.V. Boccaccini, E. Bubelis, V.P. Chakin, I. Cristescu, B.E. Ghidersa, M. Gonzalez, W. Hering, T. Hernandez, X.Z. Jin, M. Kamlah, B. Kiss, R. Knitter, M.H.H. Kolb, P. Kurinskiy, O. Leys, I.A. Maione, M. Moscardini, G. Nadasi, H. Neuberger, P. Pereslavtsev, S. Pupeschi, R. Rolli, S. Ruck, G.A. Spagnuolo, P.V. Vladimirov, C. Zeile, G. Zhou, Overview of the HCPB Research Activities in EUROfusion, IEEE Transactions on Plasma Science. 46 (2018) 22472261.

[4] M. Rieth, S.L. Dudarev, S.M.G. de Vicente, J. Aktaa, T. Ahlgren, S. Antusch, D.E.J. Armstrong, M. Balden, N. Baluc, M.-F. Barthe, W.W. Basuki, M. Battabyal, C.S. Becquart, D. Blagoeva, H. Boldyryeva, J. Brinkmann, M. Celino, L. Ciupinski, J.B. Correia, A.D. Backer, C. Domain, E. Gaganidze, C. García-Rosales, J. Gibson, M.R. Gilbert, S. Giusepponi, B. Gludovatz, H. Greuner, K. Heinola, T. Höschen, A. Hoffmann, N. Holstein, F. Koch, W. Krauss, H. Li, S. Lindig, J. Linke, C. Linsmeier, P. López-Ruiz, H. Maier, J. Matejicek, T.P. Mishra, M. Muhammed, A. Muñoz, M. Muzyk, K. Nordlund, D. Nguyen-Manh, J. Opschoor, N. Ordás, T. Palacios, G. Pintsuk, R. Pippan, J. Reiser, J. Riesch, S.G. Roberts, L. Romaner, M. Rosiński, M. Sanchez, W. Schulmeyer, H. Traxler, A. Ureña, J.G. van der Laan, L. Veleva, S. Wahlberg, M. Walter, T. Weber, T. Weitkamp, S. Wurster, M.A. Yar, J.H. You, A. Zivelonghi, Recent progress in research on tungsten materials for nuclear fusion applications in Europe, Journal of Nuclear Materials. 432 (2013) 482-500. doi:10.1016/j.jnucmat.2012.08.018.

[5] J. Davis, V. Barabash, A. Makhankov, L. Plöchl, K. Slattery, Assessment of tungsten for use in the ITER plasma facing components, Journal of Nuclear Materials. 258-263 (1998) 308-312. 
[6] CRC Handbook of Chemistry and Physics. Chapter 4 - Physical Constants of Inorganic Compounds. Page 4-97. ISBN 978-1-4200-9084-0, 90th ed., American Chemical Society (ACS), 2010. doi:10.1021/ja906434c.

[7] T. Tanabe, C. Eamchotchawalit, C. Busabok, S. Taweethavorn, M. Fujitsuka, T. Shikama, Temperature dependence of thermal conductivity in $\mathrm{W}$ and $\mathrm{W}$-Re alloys from 300 to 1000 K, Materials Letters. 57 (2003) 2950-2953. doi:10.1016/s0167577x(02)01403-9.

[8] M. Rieth, D. Armstrong, B. Dafferner, S. Heger, A. Hoffmann, M.D. Hoffmann, U. Jäntsch, C. Kübel, E. Materna-Morris, J. Reiser, M. Rohde, T. Scherer, V. Widak, $\mathrm{H}$. Zimmermann, Tungsten as a Structural Divertor Material, Advances in Science and Technology. 73 (2010) 11-21.

[9] D. Qu, W. Basuki, J. Aktaa, Numerical assessment of functionally graded tungsten/EUROFER coating system for first wall applications, Fusion Engineering and Design. 98-99 (2015) 1389-1393.

[10] T. Weber, J. Aktaa, Numerical assessment of functionally graded tungsten/steel joints for divertor applications, Fusion Engineering and Design. 86 (2011) 220-226.

[11] D. Qu, W. Basuki, J. Gibmeier, R. Vaßen, J. Aktaa, Development Of Functionally Graded Tungsten/Eurofer Coating System For First Wall Application, Fusion Science and Technology. 68 (2015) 578-581.

[12] R. Vaßen, K.-H. Rauwald, O. Guillon, J. Aktaa, T. Weber, H. Back, D. Qu, J. Gibmeier, Vacuum plasma spraying of functionally graded tungsten/EUROFER97 coatings for fusion applications, Fusion Engineering and Design. 133 (2018) 148156.

[13] T. Weber, M. Stüber, S. Ulrich, R. Vaßen, W. Basuki, J. Lohmiller, W. Sittel, J. Aktaa, Functionally graded vacuum plasma sprayed and magnetron sputtered tungsten/EUROFER97 interlayers for joints in helium-cooled divertor components, Journal of Nuclear Materials. 436 (2013) 29-39.

[14] S. Heuer, J. Matějíček, M. Vilémová, M. Koller, K. Illkova, J. Veverka, T. Weber, G. Pintsuk, J. Coenen, C. Linsmeier, Atmospheric plasma spraying of functionally graded steel / tungsten layers for the first wall of future fusion reactors, Surface Coatings and Technology. 366 (2019) 170-178.

[15] J. Matějíček, V. M., B. Nevrlá, L. Kocmanová, J. Veverka, M. Halasová, H. Hadraba, The influence of substrate temperature and spraying distance on the properties of plasma sprayed tungsten and steel coatings deposited in a shrouding chamber, Surface \& Coatings Technology. 318 (2017) 217-223.

[16] T. Emmerich, D. Qu, B.-E. Ghidersa, M. Lux, J. Rey, R. Vaßen, J. Aktaa, Development progress of coating first wall components with functionally graded 
W/EUROFER layers on laboratory scale, Nuclear Fusion. 60 (2020) 126004.

[17] D. Qu, Development of functionally graded tungsten/EUROFER coating systems (PhD thesis), 2016. doi:10.5445/IR/1000061922.

[18] D. Rapisarda, I. Fernandez, I. Palermo, M. Gonzalez, C. Moreno, A. Ibarra, E.M. de les Valls, Conceptual Design of the EU-DEMO Dual Coolant Lithium Lead Equatorial Module, IEEE Transactions on Plasma Science. 44 (2016) 1603-1612. doi:10.1109/tps.2016.2561204.

[19] A. del Nevo, E. Martelli, P. Agostini, P. Arena, G. Bongiov \'i, G. Caruso, G.D. Gironimo, P.A.D. Maio, M. Eboli, R. Giammusso, F. Giannetti, A. Giovinazzi, G. Mariano, F. Moro, R. Mozzillo, A. Tassone, D. Rozzia, A. Tarallo, M. Tarantino, M. Utili, R. Villari, WCLL breeding blanket design and integration for DEMO 2015: status and perspectives, Fusion Engineering and Design. 124 (2017) 682-686. doi:10.1016/j.fusengdes.2017.03.020.

[20] F.A. Hernández, P. Pereslavtsev, G. Zhou, H. Neuberger, J. Rey, Q. Kang, L.V. Boccaccini, E. Bubelis, I. Moscato, D. Dongiovanni, An enhanced, near-term HCPB design as driver blanket for the EU DEMO, Fusion Engineering and Design. 146 (2019) 1186-1191. doi:10.1016/j.fusengdes.2019.02.037.

[21] F. Maviglia, R. Albanese, R. Ambrosino, W. Arter, C. Bachmann, T. Barrett, G. Federici, M. Firdaous, J. Gerardin, M. Kovari, V. Loschiavo, M. Mattei, F. Villone, R. Wenninger, Wall protection strategies for DEMO plasma transients, Fusion Engineering and Design. 136 (2018) 410-414. doi:10.1016/j.fusengdes.2018.02.064.

[22] P. Pereslavtsev, C. Bachmann, U. Fischer, Neutronic analyses of design issues affecting the tritium breeding performance in different DEMO blanket concepts, Fusion Engineering and Design. 109-111 (2016) 1207-1211. doi:10.1016/j.fusengdes.2015.12.053.

[23] D. Qu, M. Wirtz, J. Linke, R. Vaßen, J. Aktaa, Thermo-mechanical response of FG tungsten/EUROFER multilayer under high thermal loads, Journal of Nuclear Materials. 519 (2019) 137-144.

[24] T. Emmerich, R. Vaßen, J. Aktaa, Thermal fatigue behavior of functionally graded W/EUROFER-layer systems using a new test apparatus, Fusion Engineering and Design. 154 (2020) 111550.

[25] European Research Roadmap to the Realisation of Fusion Energy, ISBN 978-3-00061152-0, EUROfusion Programme Management Unit, 2018.

[26] F. Hernández, P. Pereslavtsev, Q. Kang, P. Norajitra, B. Kiss, G. Nádasi, O. Bitz, A new HCPB breeding blanket for the EU DEMO: Evolution, rationale and preliminary performances, Fusion Engineering and Design. 124 (2017) 882-886. 
544

545

546

547

548

549

550

551

552

553

554

555

556

557

558

559

560

561

562

563

564

565

566

567

568

569

570

571

572

573

574

575

576

577

578

579

580

581

582

583

584

585

586

587

588

589

590

591

[27] H. Neuberger, J. Rey, A. von der Weth, F. Hernandez, T. Martin, M. Zmitko, A. Felde, R. Niewöhner, F. Krüger, Overview on ITER and DEMO blanket fabrication activities of the KIT INR and related frameworks, Fusion Engineering and Design. 96-97 (2015) 315-318. doi:10.1016/j.fusengdes.2015.06.174.

[28] L.V. Boccaccini, G. Aiello, J. Aubert, C. Bachmann, T. Barrett, A.D. Nevo, D. Demange, L. Forest, F. Hernandez, P. Norajitra, G. Porempovic, D. Rapisarda, P. Sardain, M. Utili, L. Vala, Objectives and status of EUROfusion DEMO blanket studies, Fusion Engineering and Design. 109-111 (2016) 1199-1206. doi:10.1016/j.fusengdes.2015.12.054.

[29] J. Aktaa, F. Siska, Assessment of defects in EUROFER 97 first wall/blanket structures taking into account its viscoplastic behavior, Fusion Engineering and Design. 85 (2010) 2065-2069. doi:10.1016/j.fusengdes.2010.07.023.

[30] H. Neuberger, A. von der Weth, J. Rey, KIT induced activities to support fabrication, assembly and qualification of technology for the HCPB-TBM, Fusion Engineering and Design. 86 (2011) 2039-2042. doi:10.1016/j.fusengdes.2011.03.016.

[31] M. Rasiński, A. Kreter, S. Möller, T. Schlummer, Y. Martynova, S. Brezinsek, C. Linsmeier, The microstructure of reduced activation ferritic/martensitic (RAFM) steels exposed to D plasma with different seeding impurities, Physica Scripta. T170 (2017) 014036. doi:10.1088/1402-4896/aa8de5.

[32] K. Yin, S. Qiu, R. Tang, Q. Zhang, L. Zhang, Corrosion behavior of ferritic/martensitic steel P92 in supercritical water, Journal of Supercritical Fluids. 50 (2009) 235-239. doi:10.1016/j.supflu.2009.06.019.

[33] Warmfester Stahl X10CrWMoVNb9-2 Werkstoff-Nr. 1.4901, VdTÜV-Werkstoffblatt Nr, 552/3 (09.2009) (in German), 2009.

[34] R. Lindau, A. Möslang, M. Rieth, M. Klimiankou, E. Materna-Morris, A. Alamo, A.-A. Tavassoli, C. Cayron, A.-M. Lancha, P. Fernandez, N. Baluc, R. Schäublin, E. Diegele, G. Filacchioni, J. Rensman, B. v. d. Schaaf, E. Lucon, W. Dietz, Present development status of EUROFER and ODS-EUROFER for application in blanket concepts, Fusion Engineering and Design. 75-79 (2005) 989-996.

[35] B.-J. Kim, H.-J. Kim, B.-S. Lim, Creep-Fatigue Damage and Life Prediction in P92 Alloy by Focused Ultrasound Measurements, Metals and Materials International. 14 (2008) 391-395.

[36] P. Ennis, A. Zielinska-Lipiec, O. Wachter, A. Czyrska-Filemonowicz, Microstructural Stability And Creep Rupture Strength Of The Martensitic Steel P92 For Advanced Power Plant, Acta Materialia. 12 (1997) 4901-4907.

[37] J.C. Vaillant, B. Vandenberghe, B. Hahn, H. Heuser, C. Jochum, T/P23, 24, 911 and 92: New grades for advanced coal-fired power plants ltextemdashProperties and experience, International Journal of Pressure Vessels and Piping. 85 (2008) 
[38] J. Hald, Creep strength and ductility of 9 to $12 \%$ chromium steels, Materials at High Temperatures. 21 (2004) 41-46. doi:10.1179/mht.2004.006.

[39] J. Schindelin, I. Arganda-Carreras, E. Frise, V. Kaynig, M. Longair, T. Pietzsch, S. Preibisch, C. Rueden, S. Saalfeld, B. Schmid, J.-Y. Tinevez, D. White, V. Hartenstein, K. Eliceiri, P. Tomancak, A. Cardona, Fiji: an open-source platform for biological-image analysis, Nature Methods. 9 (2012) 676-682.

[40] S. Deshpande, A. Kulkarni, S. Sampath, H. Herman, Application of image analysis for characterization of porosity in thermal spray coatings and correlation with small angle neutron scattering, Surface Coatings and Technology. 187 (2004) 6-16.

[41] T. Ridler, S. Calvard, Picture Thresholding Using an Iterative Selection Method, IEEE Transactions on Systems, Man and Cybernetics. 8 (1978) 630-632.

[42] T. Martin, S. Knaak, Y. Zhong, J. Aktaa, Ultrasonic Testing on EUROFER Welded Joints for Determination of the Minimum Detectable Flaw Size - KIT Scientific Reports 7543, ISSN 1869-9669, 2010.

[43] R. Hixson, M. Winkler, Thermophysical Properties of Solid and Liquid Tungsten, International Journal of Thermophysics. 11 (1990) 709-718.

[44] T. Martin, S. Knaak, W. Basuki, J. Aktaa, J. Rey, A. von der Weth, Automated ultrasonic immersion testing of fusion reactor components: implementation and evaluation with high accuracy (poster), in: DGZfP-Jahrestagung 2013, 2013.

[45] T. Emmerich, D. Qu, R. Vaßen, J. Aktaa, Development of W-coating with functionally graded W/EUROFER-layers for protection of First-Wall materials, Fusion Engineering and Design. 128 (2018) 58-67.

[46] T. Tokunaga, H. Watanabe, N. Yoshida, T. Nagasaka, R. Kasada, A. Kimura, M. Tokitani, M. Mitsuhara, H. Nakashima, S. Masuzaki, T. Takabatake, N. Kuroki, K. Ezato, S. Suzuki, M. Akiba, Manufacture of Vacuum Plasma Spraying Tungsten with Homogenous Texture on Reduced Activation Ferritic Steel at about $873 \mathrm{~K}$, Plasma and Fusion Research. 8 (2013) 1405111.

[47] D. Qu, E. Gaganidze, R. Vaßen, J. Aktaa, Determination of interface toughness of functionally graded tungsten/EUROFER multilayer at $550^{\circ} \mathrm{C}$ by analytical and experimental methods, Engineering Fracture Mechanics. 202 (2018) 487-499.

[48] L. Pawlowski, The Science and Engineering of Thermal Spray Coatings. Chapter 8 - Properties of Coatings. ISBN 9780471490494, 2nd ed., Wiley, 2008. doi:10.1002/9780470754085.ch8.

[49] Y. Yahiro, M. Mitsuhara, K. Tokunakga, N. Yoshida, T. Hirai, K. Ezato, S. Suzuki, M. Akiba, H. Nakashima, Characterization of thick plasma spray tungsten coating 
640

643

644

645

646

647

on ferritic/martensitic steel $\mathrm{F} 82 \mathrm{H}$ for high heat flux armor, Journal of Nuclear Materials. 386-388 (2009) 784-788.

[50] R. Anderl, R. Pawelko, M. Hankins, G. Longhurst, R. Neiser, Hydrogen permeation properties of plasma-sprayed tungsten, Journal of Nuclear Materials. 212-215 (1994) 1416-1420. 